\title{
COX-2 rs689466, rs5275, and rs20417 polymorphisms and risk of head and neck squamous cell carcinoma: a meta-analysis of adjusted and unadjusted data
}

Wei-Dong Leng ${ }^{1+}$, Xiu-Jie Wen ${ }^{2+}$, Joey S. W. Kwong ${ }^{3+}$, Wei Huang ${ }^{4}$, Jian-Gang Chen ${ }^{5}$ and Xian-Tao Zeng ${ }^{1,5^{*}}$

\begin{abstract}
Background: Numerous case-control studies have been performed to investigate the association between three cyclooxygenase-2 (COX-2) polymorphisms (rs20417 (-765G > C), rs689466 (-1195G > A), and rs5275 (8473 T > C)) and the risk of head and neck squamous cell carcinoma (HNSCC). However, the results were inconsistent. Therefore, we conducted this meta-analysis to investigate the association.

Methods: We searched in PubMed, Embase, and Web of Science up to January 20, 2015 (last updated on May 12, 2016). Two independent reviewers extracted the data. Odds ratios (ORs) with their $95 \%$ confidence intervals (Cls) were used to assess the association. All statistical analyses were performed using the Review Manager (RevMan) 5.2 software.

Results: Finally 8 case-control studies were included in this meta-analysis. For unadjusted data, an association with increased risk was observed in three genetic models in COX-2 rs689466 polymorphism; however, COX-2 rs5275 and rs20417 polymorphisms were not related to HNSCC risk in this study. The pooled results from adjusted data all revealed non-significant association between these three polymorphisms and risk of HNSCC. We also found a similar result in the subgroup analyses, based on both unadjusted data and adjusted data.
\end{abstract}

Conclusion: Current results suggest that COX-2 rs689466, rs5275, and rs20417 polymorphisms are not associated with HNSCC. Further large and well-designed studies are necessary to validate this association.

Keywords: COX-2 rs689466, COX-2 rs5275, COX-2 rs20417, Polymorphism, Head and neck squamous cell carcinoma, Meta-analysis

\section{Background}

Head and neck squamous cell carcinoma (HNSCC) is 1 of the disease burdens worldwide affecting eating, breathing, and appearance. Besides environmental risk factors, such as tooth loss [1], alcohol consumption [2], periodontal diseases [3], smoking [4], tooth

\footnotetext{
*Correspondence: zengxiantao1128@163.com

${ }^{\dagger}$ Equal contributors

'Department of Stomatology, Taihe Hospital, Institute of Oral and Maxillofacial Surgery, Hubei University of Medicine, Shiyan 442000, China ${ }^{5}$ Department of Stomatology, Center for Evidence-Based and Translational Medicine, Zhongnan Hospital of Wuhan University, 169 Donghu Road, Wuhan 430071, China

Full list of author information is available at the end of the article
}

brushing [5], and human papillomavirus (HPV) [6], genetic factors $[7,8]$ also play an significant role in the onset and development of HNSCC. Many polymorphisms have been identified associated with risk of HNSCC by meta-analyses, such as the hOGG1 Ser326Cys polymorphism [9], XRCC1 Arg194Trp polymorphism [10], ERCC2 rs1799793 and rs13181 polymorphisms [11]; however, some polymorphisms including XPD Asp312Asn polymorphism [12], TP53 codon 72 polymorphism [7], and VEGF gene polymorphisms [13] are not associated with HNSCC risk. Particularly within the same gene, theXRCC1gene for example, XRCC1 Arg194Trp polymorphism was 
associated with increased risk while Arg399Gln and Arg280His polymorphisms were not [10].

The human cyclooxygenase-2 (COX-2), the key enzyme in the conversion of arachidonic acid to prostatglandins, is located at chromosome 1q25.2-q25.3 and rs20417 $(-765 \mathrm{G}>\mathrm{C})$, rs689466 $(-1195 \mathrm{G}>\mathrm{A})$, and rs5275 $(8473 \mathrm{~T}>\mathrm{C})$ are the three commonly investigated polymorphisms in the COX-2 gene $[14,15]$. Now the association between COX-2 gene polymorphisms and risk of many cancers, such as hepatocellular carcinoma [16], colorectal cancer [17], breast cancer [18], prostate cancer [19], gastric cancer [20] were investigated by meta-analyses. COX-2 has been confirmed very low or no expression in normal human oral tissues, otherwise it was elevated in oral precancerous lesions and over-expressed in oral squamous cell carcinoma (OSCC) [21]. The elevated expression of COX-2 was presented to be correlated with malignant transformation, advancing clinical stage, and disease progression [22].

There are also many published studies that explored the association between COX-2 rs689466, rs5275, and rs20417 polymorphisms and risk of HNSCC.
Unfortunately, the results of published studies were inconsistent and using a meta-analytic method to pool these results for obtaining a more precise result [23] is necessary. In this meta-analysis, we extracted and combined crude data and adjusted data.

\section{Methods}

We reported this meta-analysis according to the Preferred Reporting Items for Systematic Reviews and MetaAnalyses (PRISMA) statement [24] and ethical approval is not necessary.

\section{Eligibility criteria}

Cohort studies or case-control studies evaluating the risk of HNSCC in relation to COX-2 rs689466, rs5275, and/or rs20417 polymorphisms were considered for eligibility if they also met the following criteria: (1) the cancer was HNSCC, oral squamous cell carcinoma (OSCC), or laryngeal squamous cell carcinoma (LSCC) confirmed using microscopic examination; (2) the frequency of genotype distribution, adjusted odds ratios (ORs) and their $95 \%$ confidence intervals (CIs), or the data that can calculate them

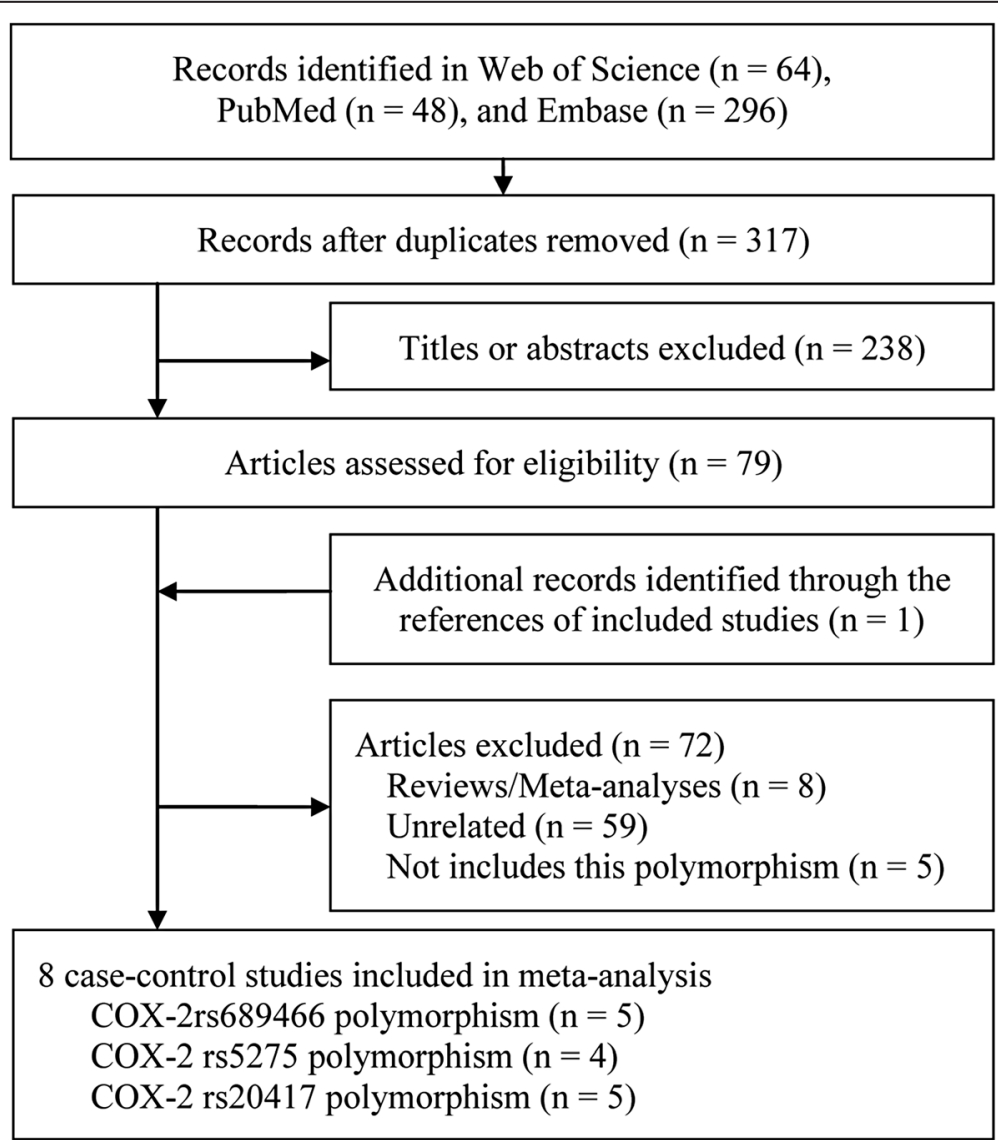

Fig. 1 Study selection flowchart 
Table 1 Characteristics and unadjusted data of included studies

\begin{tabular}{|c|c|c|c|c|c|c|c|c|c|}
\hline \multirow{3}{*}{$\begin{array}{l}\text { Study } \\
\text { rs689466 (-1195G > A) }\end{array}$} & \multirow[t]{3}{*}{ Country (Ethnicity) } & \multirow{3}{*}{$\begin{array}{l}\text { Form of } \\
\text { disease }\end{array}$} & \multicolumn{4}{|c|}{ Cases/Control } & \multirow[t]{3}{*}{ HWE } & \multirow{3}{*}{$\begin{array}{l}\text { Smoking } \\
\text { status }\end{array}$} & \multirow{3}{*}{$\begin{array}{l}\text { Genotyping } \\
\text { methods }\end{array}$} \\
\hline & & & \multirow[t]{2}{*}{ Sample size } & \multicolumn{3}{|c|}{ Genotype distribution } & & & \\
\hline & & & & GG & GA & $\mathrm{AA}$ & & & \\
\hline Chiang 2008 & China (Asian) & oscC & $368 / 441$ & $80 / 114$ & $187 / 235$ & $101 / 92$ & Yes & Mixed & PCR-RFLP \\
\hline Peters 2009 & Netherlands (Caucasian) & HNSCC & $431 / 438$ & $275 / 260$ & $134 / 163$ & $22 / 15$ & Yes & Mixed & $P C R$ \\
\hline Mittal 2010 & India (Asian) & oscC & 193/137 & $3 / 5$ & $57 / 32$ & $133 / 100$ & Yes & Smokers & PCR-RFLP \\
\hline Chang 2013 & China (Asian) & HNSCC & $313 / 295$ & $93 / 90$ & $146 / 148$ & $74 / 57$ & Yes & Mixed & Taqman \\
\hline \multirow[t]{3}{*}{ Niu 2014} & China (Asian) & HNSCC & $259 / 1035$ & $61 / 222$ & $126 / 542$ & $72 / 271$ & Yes & Mixed & Taqman \\
\hline & & oscC & $140 / 1035$ & $44 / 222$ & $80 / 542$ & $25 / 271$ & Yes & Mixed & Taqman \\
\hline & & LSCC & $90 / 1035$ & $17 / 222$ & $46 / 542$ & $27 / 271$ & Yes & Mixed & Taqman \\
\hline rs5275 (8473 T > C) & & & & $\pi$ & $\mathrm{TC}$ & $\mathrm{CC}$ & & & \\
\hline \multirow[t]{3}{*}{ Campa 2007} & European (multicenter) & HNSCC & $553 / 711$ & $252 / 313$ & $237 / 321$ & $44 / 77$ & Yes & Mixed & TaqMan \\
\hline & & oscC & $252 / 711$ & $113 / 313$ & $117 / 321$ & $22 / 77$ & Yes & Mixed & TaqMan \\
\hline & & LSCC & $281 / 711$ & $139 / 313$ & $120 / 321$ & $22 / 77$ & Yes & Mixed & TaqMan \\
\hline Mittal 2010 & India (Asian) & oscc & $135 / 59$ & $74 / 24$ & $53 / 34$ & $8 / 1$ & No & Smokers & PCR-RFLP \\
\hline Chang 2013 & China (Asian) & HNSCC & $313 / 295$ & 209/199 & $89 / 86$ & $15 / 10$ & Yes & Mixed & Taqman \\
\hline \multirow[t]{3}{*}{ Niu 2014} & China (Asian) & HNSCC & $258 / 1032$ & $177 / 691$ & $72 / 316$ & $9 / 25$ & Yes & Mixed & Taqman \\
\hline & & oscC & 168/1032 & $118 / 691$ & $45 / 316$ & $5 / 25$ & Yes & Mixed & Taqman \\
\hline & & LSCC & $90 / 1032$ & $59 / 691$ & $27 / 316$ & $4 / 25$ & Yes & Mixed & Taqman \\
\hline rs20417 (-765G > C) & & & & GG & GC & $\mathrm{CC}$ & & & \\
\hline Lin 2008 & China (Asian) & oscc & $297 / 280$ & 193/107 & $104 / 173$ & $0 / 0$ & Yes & Mixed & PCR-RFLP \\
\hline Chiang 2008 & China (Asian) & oscC & $178 / 205$ & 136/166 & $42 / 39$ & $0 / 0$ & Yes & Mixed & PCR-RFLP \\
\hline Peters 2009 & Netherlands (Caucasian) & HNSCC & $428 / 433$ & $321 / 321$ & 99/99 & $8 / 13$ & Yes & Mixed & $P C R$ \\
\hline Mittal 2010 & India (Asian) & OsCC & $176 / 96$ & $92 / 41$ & $78 / 49$ & $6 / 6$ & Yes & Smokers & PCR-RFLP \\
\hline Lakshmi 2012 & India (Asian) & OsCC & 150/150 & 110/142 & $28 / 6$ & $12 / 2$ & No & Mixed & PCR-RFLP \\
\hline
\end{tabular}


Table 2 Adjustment and adjusted data of included studies

\begin{tabular}{|c|c|c|c|c|}
\hline Study & Form of disease & Reference & OR $(95 \% \mathrm{Cl})$ & Adjustment \\
\hline \multicolumn{5}{|c|}{ rs689466 $(-1195 G>A)$} \\
\hline \multirow[t]{2}{*}{ Peters 2009} & \multirow[t]{2}{*}{ HNSCC } & \multirow[t]{2}{*}{ GG: 1.00} & GA: $0.79(0.58-1.07) ;$ & \multirow{2}{*}{$\begin{array}{l}\text { age (continuous), sex, smoking (continuous, } 5 \text { levels), } \\
\text { and alcohol consumption (continuous, } 3 \text { levels) }\end{array}$} \\
\hline & & & AA: $1.24(0.60-2.56)$ & \\
\hline \multirow[t]{3}{*}{ Mittal 2010} & \multirow[t]{3}{*}{ OsCC } & \multirow[t]{2}{*}{ GG: 1.00} & GA: $3.07(0.66-13.24) ;$ & \multirow[t]{3}{*}{ age, gender } \\
\hline & & & AA: $2.22(0.52-9.50)$ & \\
\hline & & G: 1.00 & A: $1.03(0.60-1.42)$ & \\
\hline \multirow[t]{4}{*}{ Chang 2013} & \multirow[t]{4}{*}{ HNSCC } & \multirow[t]{3}{*}{ GG: 1.00} & GA: $0.86(0.56-1.32) ;$ & \multirow{4}{*}{$\begin{array}{l}\text { sex, age, education, cigarette smoking (pack-year categories), } \\
\text { betel quid chewing (pack-year categories), and alcohol } \\
\text { drinking (frequency) }\end{array}$} \\
\hline & & & AA: $1.23(0.72-2.09)$ & \\
\hline & & & $\mathrm{GA}+\mathrm{AA}: 0.96(0.64-1.43) ;$ & \\
\hline & & G: 1.00 & A: $1.08(0.83-1.40)$ & \\
\hline \multirow[t]{9}{*}{ Niu 2014} & \multirow[t]{3}{*}{ HNSCC } & \multirow[t]{3}{*}{ GG: 1.00} & GA:0.85 (0.60-1.21) & \multirow[t]{9}{*}{ age, sex, smoking status, and drinking status } \\
\hline & & & AA: $1.01(0.69-1.50)$ & \\
\hline & & & GA + AA: $0.91(0.65-1.26)$ & \\
\hline & \multirow[t]{3}{*}{ OSCC } & \multirow[t]{3}{*}{ GG: 1.00} & GA: $0.74(0.49-1.11)$ & \\
\hline & & & AA: $0.87(0.55-1.39)$ & \\
\hline & & & $\mathrm{GA}+\mathrm{AA}: 0.78(0.53-1.14)$ & \\
\hline & \multirow[t]{3}{*}{ LSCC } & \multirow[t]{3}{*}{ GG: 1.00} & GA:1.16 (0.65-2.09) & \\
\hline & & & AA:1.43 (0.75-2.75) & \\
\hline & & & $\mathrm{GA}+\mathrm{AA}: 1.23(0.71-2.15)$ & \\
\hline \multicolumn{5}{|c|}{ rs5275 (8473 T>C) } \\
\hline \multirow[t]{9}{*}{ Campa 2007} & \multirow[t]{3}{*}{ HNSCC } & TT: 1.00 & TC: $1.03(0.82-1.28)$ & age, sex, center, tobacco consumption (packyears), \\
\hline & & & CC: $0.75(0.51-1.10)$ & 10 \\
\hline & & & $\mathrm{TC}+\mathrm{CC}: 0.97(0.78-1.20)$ & \\
\hline & OPSCC & Tा: 1.00 & TC: $1.16(0.86-1.58) ;$ & \\
\hline & & & CC: $0.91(0.53-1.54) ;$ & \\
\hline & & & TC + CC: $1.11(0.83-1.49)$ & \\
\hline & LSCC & TT: 1.00 & TC: $0.88(0.63-1.22)$ & \\
\hline & & & CC: $0.60(0.34-1.05) ;$ & \\
\hline & & & $\mathrm{TC}+\mathrm{CC}: 0.82(0.60-1.12)$ & \\
\hline Mittal 2010 & OSCC & $\pi: 1.00$ & TC: $0.27(0.03-2.26) ;$ & age, gender \\
\hline & & & CC: $0.28(0.03-2.33)$ & \\
\hline & & $\mathrm{T}: 1.00$ & C: $0.88(0.55-1.40)$ & \\
\hline Chang 2013 & HNSCC & Tा: 1.00 & TC: $1.04(0.69-1.56) ;$ & sex, age, education, cigarette smoking (pack-year \\
\hline & & & CC: $1.89(0.74-4.82) ;$ & $\begin{array}{l}\text { categorles), betel quid chewing (pack-year categorles), } \\
\text { and alcohol drinking (frequency) }\end{array}$ \\
\hline & & & TC + CC: $1.12(0.75-1.65)$ & \\
\hline Niu 2014 & HNSCC & $\pi: 1.00$ & TC: $0.90(0.66-1.22) ;$ & age, sex, smoking status, and drinking status \\
\hline & & & CC: $1.48(0.68-3.25)$ & \\
\hline & & & $\mathrm{TC}+\mathrm{CC}: 0.94(0.70-1.26)$ & \\
\hline & OsCC & Tा: 1.00 & TC: $0.86(0.58-1.26) ;$ & \\
\hline & & & CC: $1.03(0.36-2.97) ;$ & \\
\hline & & & $\mathrm{TC}+\mathrm{CC}: 0.87(0.60-1.27)$ & \\
\hline & LSCC & ПT: 1.00 & TC: $1.02(0.63-1.64) ;$ & \\
\hline & & & CC: 1.62 (0.54-4.88); & \\
\hline & & & $\mathrm{TC}+\mathrm{CC}: 1.07(0.67-1.69)$ & \\
\hline
\end{tabular}


Table 2 Adjustment and adjusted data of included studies (Continued)

\begin{tabular}{|c|c|c|c|c|}
\hline \multicolumn{5}{|c|}{ rs20417 (-765G >C) } \\
\hline $\operatorname{Lin} 2008$ & oscC & GG: 1.00 & GC + CC: $0.22(0.12-0.39)$ & $\begin{array}{l}\text { age, gender, ethnicity, educational level, and habits of bete } \\
\text { quid chewing, cigarette smoking, and alcohol drinking }\end{array}$ \\
\hline \multirow[t]{2}{*}{ Peters 2009} & \multirow[t]{2}{*}{ HNSCC } & \multirow[t]{2}{*}{ GG: 1.00} & GC: 0.99 (0.71-1.40); & \multirow{2}{*}{$\begin{array}{l}\text { age (continuous), sex, smoking (continuous, } 5 \text { levels), and } \\
\text { alcohol consumption (continuous, } 3 \text { levels) }\end{array}$} \\
\hline & & & CC: $0.59(0.23-1.49)$ & \\
\hline \multirow[t]{3}{*}{ Mittal 2010} & \multirow[t]{3}{*}{ oscC } & GG: 1.00 & GC: 0.71 (0.42-1.18); & \multirow[t]{3}{*}{ age, gender } \\
\hline & & & CC: $0.44(0.13-1.46)$ & \\
\hline & & G: 1.00 & C: $0.73(0.50-1.08)$ & \\
\hline
\end{tabular}

OSCC oral squamous cell carcinoma; HNSCC head and neck squamous cell carcinoma; LSCC laryngeal squamous cell carcinoma; OR odds ratio; CI confidence interval

were reported; (3) full-text were obtainable; (4) if 2 or more studies covered the same population, we included the study that contained most comprehensive information; (5) the published language is English or Chinese.

\section{Search strategy}

We searched PubMed, Embase, and Web of Science up to January 20, 2015 (last updated on May 12, 2016) using the following search terms: head and neck, oral, oral cavity, pharyngeal, oropharynx, laryngeal, laryngopharyngeal, mouth, tongue, carcinoma, cancer, tumour, neoplasm, cyclooxygenase-2, COX-2, PTGs2, polymorphism, mutation, variant, and variation. We also screened reference lists of recent reviews, eligible studies, and published meta-analyses on related topics for additional eligible studies.

\section{Data extraction}

The following data were extracted from all eligible studies by 2 authors independently and disagreements $(\kappa=0.96)$ were resolved by discussion: last name of the first author; publication year; country and ethnicity; genotyping method; source of control, number and genotyping distribution of cases and controls; adjusted OR and its $95 \% \mathrm{CI}$; adjusted variables; and
Hardy-Weinberg Equilibrium (HWE) for controls [25]. The meta-analysis reviewers were blind to the study author and institution of the studies undergoing review.

\section{Statistical analysis}

The heterogeneity was assessed first using the Cochrane $Q$ and $I^{2}$ statistic [26]. The heterogeneity was considered acceptable if both $p>0.1$ and $I^{2}<40 \%$ and used the fixed effect model, otherwise the random effect model was used. For crude data, we used OR and its $95 \%$ confidence interval (CI) to quantify the strength of association using the allele comparison, homozygote comparison, heterozygote comparison, dominant model, and recessive model genetic models. For adjusted data, we directly combined the relevant ORs and their $95 \%$ CIs according to reported genetic models. We performed subgroup analyses based on ethnicity, site of cancer, and HWE status for controls. The sensitivity analysis was performed by switching the effect model. Publication bias was assessed by funnel plots if the number of included studies was more than 9 . All statistical analyses were performed using Review Manager (RevMan) software (version 5.2 for Windows; Copenhagen: The Nordic Cochrane Centre, The Cochrane Collaboration).

\begin{tabular}{|c|c|c|c|c|c|c|c|c|c|}
\hline Study or Subgroup & $\begin{array}{l}\text { Cases } \\
\text { Events }\end{array}$ & Total & $\begin{array}{l}\text { Contro } \\
\text { Events }\end{array}$ & $\begin{array}{l}\text { ols } \\
\text { Total }\end{array}$ & Weight & $\begin{array}{l}\text { Odds Ratio } \\
\text { M-H, Fixed, } 95 \% \mathrm{Cl} \text { Year }\end{array}$ & $\begin{array}{r}\text { Odds } \\
\text { M-H, Fixe }\end{array}$ & $\begin{array}{l}\text { Ratio } \\
\text { ed, } 95 \% \mathrm{Cl}\end{array}$ & \\
\hline Chiang 2008 & 389 & 736 & 419 & 882 & $25.0 \%$ & $1.24[1.02,1.51] 2008$ & & & \\
\hline Peters 2009 & 178 & 862 & 193 & 876 & $21.1 \%$ & $0.92[0.73,1.16] 2009$ & 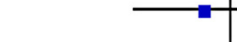 & & \\
\hline Mittal 2010 & 323 & 386 & 232 & 274 & $6.2 \%$ & $0.93[0.61,1.42] 2010$ & & & \\
\hline Chang 2013 & 294 & 626 & 262 & 590 & $19.9 \%$ & $1.11[0.88,1.39] 2013$ & & & \\
\hline Niu 2014 & 270 & 518 & 1048 & 2070 & $27.9 \%$ & $1.06[0.88,1.29] 2014$ & & & \\
\hline Total $(95 \% \mathrm{Cl})$ & & 3128 & & 4692 & $100.0 \%$ & $1.08[0.97,1.19]$ & & & \\
\hline Total events & 1454 & & 2154 & & & & & & \\
\hline $\begin{array}{l}\text { Heterogeneity: } \mathrm{Chi}^{2}= \\
\text { Test for overall effect: }\end{array}$ & $\begin{array}{l}30, \mathrm{df}=4 \\
=1.44(\mathrm{P}\end{array}$ & $\begin{array}{l}4(P=0 \\
=0.15\end{array}$ & $\begin{array}{l}.37) ; 1^{2}= \\
\text { ) }\end{array}$ & $7 \%$ & & & 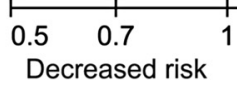 & $1 \quad 1.5$ & 2 \\
\hline
\end{tabular}


Table 3 Overall and subgroups meta-analysis of COX-2 rs689466 polymorphism and HNSCC risk

\begin{tabular}{|c|c|c|c|}
\hline Overall and subgroups & No. & OR $(95 \% \mathrm{Cl})$ & Heterogeneity $\left(1^{2} \% / \mathrm{p}\right)$ \\
\hline \multicolumn{4}{|c|}{ A vs. G (unadjusted and adjusted) } \\
\hline Overall (unadjusted) & 5 & $1.08(0.97-1.09)$ & $7 \% / 0.37$ \\
\hline Overall (adjusted) & 2 & $1.07(0.84-1.36)$ & $0 \% / 0.88$ \\
\hline Asians (unadjusted) & 4 & $1.12(1.00-1.25)$ & $0 \% / 0.56$ \\
\hline Asians (adjusted) & 2 & $1.07(0.84-1.36)$ & $0 \% / 0.88$ \\
\hline Caucasian (unadjusted) & 1 & $0.92(0.73-1.16)$ & NA \\
\hline OSCC (unadjusted) & 3 & $1.01(0.87-1.16)$ & $80 \% / 0.008$ \\
\hline OSCC (adjusted) & 1 & $1.03(0.60-1.42)$ & NA \\
\hline LSCC (unadjusted) & 1 & $0.96(0.72-1.32)$ & NA \\
\hline \multicolumn{4}{|l|}{ AA vs. GG (unadjusted) } \\
\hline Overall & 5 & $1.26(1.01-1.57)$ & $0 \% / 0.46$ \\
\hline Asians & 4 & $1.25(0.99-1.57)$ & $14 \% / 0.32$ \\
\hline Caucasian & 1 & $1.39(0.70-2.73)$ & NA \\
\hline OsCC & 3 & $1.07(0.40-2.86)$ & $86 \% /<0.05$ \\
\hline LSCC & 1 & $1.30(0.69-2.45)$ & NA \\
\hline \multicolumn{4}{|c|}{ AA vs. GA (unadjusted and adjusted) } \\
\hline Overall (unadjusted) & 5 & $1.21(1.01-1.45)$ & $28 \% / 0.23$ \\
\hline Overall (adjusted) & 4 & $0.84(0.69-1.03)$ & $0 \% / 0.41$ \\
\hline Asians (unadjusted) & 4 & $1.17(0.97-1.42)$ & $30 \% / 0.23$ \\
\hline Asians (adjusted) & 3 & $0.89(0.68-1.16)$ & $23 \% / 0.27$ \\
\hline Caucasian (unadjusted) & 1 & $1.78(0.89-3.57)$ & NA \\
\hline Caucasian (adjusted) & 1 & $0.79(0.58-1.07)$ & NA \\
\hline OSCC (unadjusted) & 3 & $0.88(0.53-1.48)$ & $76 \% / 0.01$ \\
\hline OSCC (adjusted) & 2 & $1.23(0.23-4.70)$ & $67 \% / 0.08$ \\
\hline LSCC (unadjusted) & 1 & $1.17(0.71-1.93)$ & NA \\
\hline LSCC (adjusted) & 1 & $1.16(0.65-2.09)$ & NA \\
\hline \multicolumn{4}{|l|}{ AA vs. GG + GA (unadjusted) } \\
\hline Overall & 5 & $1.20(1.01-1.43)$ & $12 \% / 0.34$ \\
\hline Asians & 4 & $1.18(0.99-1.41)$ & $26 \% / 0.26$ \\
\hline Caucasian & 1 & $1.52(0.78-2.96)$ & NA \\
\hline OscC & 3 & $0.89(0.50-1.58)$ & $83 \% / 0.003$ \\
\hline LSCC & 1 & $1.21(0.75-1.94)$ & NA \\
\hline \multicolumn{4}{|c|}{ AA + GA vs. GG (unadjusted and adjusted) } \\
\hline Overall (unadjusted) & 5 & $0.98(0.84-1.15)$ & $28 \% / 0.23$ \\
\hline Overall (adjusted) & 2 & $0.93(0.72-1.21)$ & $0 \% / 0.84$ \\
\hline Asians (unadjusted) & 4 & $1.07(0.88-1.29)$ & $13 \% / 0.33$ \\
\hline Asians (adjusted) & 2 & $0.93(0.72-1.21)$ & $0 \% / 0.84$ \\
\hline Caucasian & 1 & $0.83(0.63-1.09)$ & NA \\
\hline OSCC (unadjusted) & 3 & $1.03(0.57-1.88)$ & $75 \% / 0.02$ \\
\hline OSCC (adjusted) & 1 & $0.78(0.53-1.14)$ & NA \\
\hline LSCC (unadjusted) & 1 & $1.17(0.68-2.03)$ & NA \\
\hline LSCC (adjusted) & 1 & $1.23(0.71-2.15)$ & NA \\
\hline
\end{tabular}

OSCC oral squamous cell carcinoma; HNSCC head and neck squamous cell carcinoma; LSCC laryngeal squamous cell carcinoma; OR odds ratio; $C l$ confidence interval; $N A$ not available 


\section{Results}

\section{Study identification and characteristics}

We yielded 408 papers initially and 8 case-control studies [27-34] were included finally, Fig. 1 showed the progress of study selection. Of them, 5 case-control studies involving 1564 cases and 2346 controls focused on COX-2 rs689466 polymorphism [28, 30, 31, 33, 34], 4 studies involving 1259 cases and 2097 controls on COX-2 rs5275 polymorphism [27, 31, 33, 34], and 5 studies involving 1229 cases and 1164 controls on COX-2 rs20417 polymorphism [28-32]. One study did not satisfy the HWE for COX-2 rs5275 polymorphism [31] 1 for COX-2 rs20417 polymorphism [32]. The main characteristics are shown in Table 1 and Table 2.

\section{COX-2 rs689466 polymorphism and HNSCC risk}

The pooled results from crude data indicated there was a significant increased risk of association between COX-2 rs689466 polymorphism and HNSCC risk in AA vs. GG, AA vs. GA, and AA vs. GG + GA genetic models while no association in A vs. G (Fig. 2) and AA + GA vs. GG genetic models. Subgroup analyses stratified by ethnicity and cancer site all revealed negative results. The results of adjusted data showed no association between COX-2 rs689466 polymorphism and HNSCC risk in overall population and subgroup analyses. The sensitivity analysis showed the results without substantive change. Table 3 showed the results of all analyses.

\section{COX-2 rs5275 polymorphism and HNSCC risk}

The pooled results of crude and adjusted data all showed nonsignificant association between COX-2 rs5275 polymorphism and HNSCC risk in overall population, Fig. 3 showed the result of $\mathrm{C}$ vs. $\mathrm{T}$ model of crude data. The results of subgroup analyses all revealed negative association. The sensitivity analysis showed the results without substantive change. Table 4 showed the results of all analyses.

\section{COX-2 rs20417 polymorphism and HNSCC risk}

Table 5 presented the results of COX-2 rs20417 polymorphism and HNSCC risk. All results from unadjusted data and adjusted data presented nonsignificant association, either in overall or subgroups population; Fig. 4 showed the result of $\mathrm{C}$ vs. $\mathrm{G}$ model of crude data. The sensitivity analysis showed the results without substantive change.

\section{Publication bias}

Due to the limited number of included studies, we did not conduct publication bias analysis.

\section{Discussion}

The rs20417, rs689466, and rs5275 polymorphisms are the three commonly investigated polymorphisms in the COX-2 gene [14, 15]. In 2007, Campa D et al. conducted a case-control study including 533 cases and 1066 controls which indicated no significant association between COX-2 rs5275 polymorphism and HNSCC risk [27]. Then Chiang SL et al., in 2008, showed that COX-2 rs20417 polymorphism was not associated with OSCC risk but COX-2 rs689466 was associated with increased risk of OSCC [28]. However, another study obtained this increased risk between COX-2 rs20417 polymorphism and OSCC [29]. Similarly, published studies on these three polymorphisms revealed inconsistent results. This meta-analysis based on the crude data indicated there might be an association with increased risk of HNSCC in COX-2 rs689466 polymorphism, but identified negative association between COX-2 rs5275 and COX-2 rs20417 polymorphisms and HNSCC risk. However, the combined results of adjusted data all yielded nonsignificant associations between these three polymorphisms and HNSCC risk. The subgroup analyses according to ethnicity and sites of HNSCC confirm this negative association.

This meta-analysis is the first study to investigate these three polymorphisms and risk of HNSCC. Unlike the

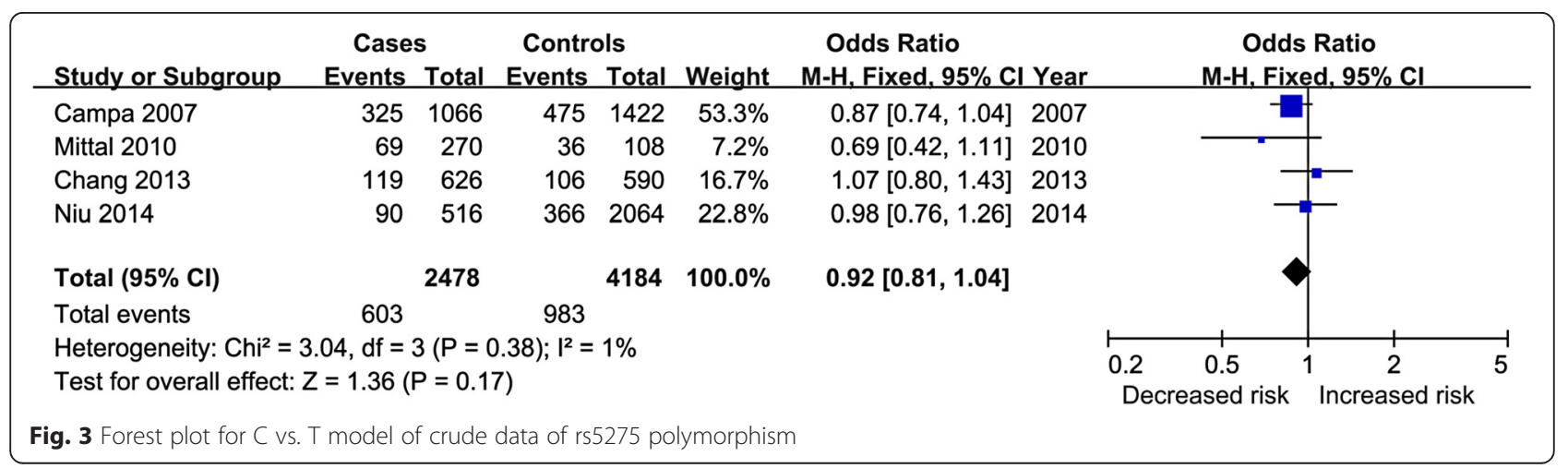


Table 4 Overall and subgroups meta-analysis of COX-2 rs5275 polymorphism and HNSCC risk

\begin{tabular}{|c|c|c|c|}
\hline Overall and subgroups & No. & OR $(95 \% \mathrm{Cl})$ & Heterogeneity $\left(R^{2} \% / p\right)$ \\
\hline \multicolumn{4}{|c|}{ C vs. T (unadjusted and adjusted) } \\
\hline Overall (unadjusted) & 4 & $0.92(0.81-1.04)$ & $1 \% / 0.38$ \\
\hline Overall (adjusted) & 2 & $1.06(0.81-1.40)$ & $0 \% / 0.33$ \\
\hline HWE (Yes-unadjusted) & 3 & $0.94(0.82-1.06)$ & $0 \% / 0.45$ \\
\hline HWE (No-unadjusted) & 1 & $0.69(0.42-1.11)$ & NA \\
\hline Asians (unadjusted) & 3 & $0.97(0.87-1.16)$ & $17 \% / 0.30$ \\
\hline Asians (adjusted) & 2 & $1.06(0.81-1.40)$ & $0 \% / 0.33$ \\
\hline Caucasian (unadjusted) & 1 & $0.87(0.74-1.04)$ & NA \\
\hline OSCC (unadjusted) & 3 & $0.90(0.76-1.06)$ & $0 \% / 0.52$ \\
\hline OSCC (adjusted) & 1 & $0.88(0.55-1.40)$ & NA \\
\hline LSCC (unadjusted) & 2 & $0.88(0.73-1.06)$ & $47 \% / 0.17$ \\
\hline \multicolumn{4}{|c|}{ CC vs. TT (unadjusted and adjusted) } \\
\hline Overall (unadjusted) & 4 & $0.92(0.67-1.27)$ & $36 \% / 0.19$ \\
\hline Overall (adjusted) & 4 & $0.92(0.67-1.27)$ & $49 \% / 0.12$ \\
\hline HWE (Yes-unadjusted) & 3 & $0.89(0.64-1.24)$ & $47 \% / 0.15$ \\
\hline HWE (No-unadjusted) & 1 & $2.59(0.31-21.82)$ & NA \\
\hline Asians (unadjusted) & 3 & $1.49(0.87-2.57)$ & $0 \% / 0.86$ \\
\hline Asians (adjusted) & 3 & $1.45(0.81-2.59)$ & $16 \% / 0.30$ \\
\hline Caucasian (unadjusted) & 1 & $0.71(0.47-1.07)$ & NA \\
\hline Caucasian (adjusted) & 1 & $0.75(0.51-1.10)$ & NA \\
\hline OSCC (unadjusted) & 3 & $0.92(0.59-1.43)$ & $0 \% / 0.48$ \\
\hline OSCC (adjusted) & 3 & $0.89(0.56-1.40)$ & $0 \% / 0.57$ \\
\hline LSCC (unadjusted) & 2 & $0.98(0.35-2.75)$ & $67 \% / 0.08$ \\
\hline LSCC (adjusted) & 2 & $0.88(0.34-2.26)$ & $60 \% / 0.12$ \\
\hline \multicolumn{4}{|c|}{ CC vs. CT (unadjusted and adjusted) } \\
\hline Overall (unadjusted) & 4 & $1.02(0.74-1.41)$ & $48 \% / 0.12$ \\
\hline Overall (adjusted) & 4 & $0.99(0.84-1.16)$ & $0 \% / 0.60$ \\
\hline HWE (Yes-unadjusted) & 3 & $0.96(0.68-1.33)$ & $42 \% / 0.18$ \\
\hline HWE (No-unadjusted) & 1 & $5.13(0.61-42.88)$ & NA \\
\hline Asians (unadjusted) & 3 & $1.73(0.99-3.01)$ & $0 \% / 0.54$ \\
\hline Asians (adjusted) & 3 & $0.93(0.73-1.19)$ & $0 \% / 0.49$ \\
\hline Caucasian (unadjusted) & 1 & $0.77(0.52-1.16)$ & NA \\
\hline Caucasian (adjusted) & 1 & $1.03(0.82-1.28)$ & NA \\
\hline OSCC (unadjusted) & 3 & $0.99(0.64-1.53)$ & $44 \% / 0.17$ \\
\hline OSCC (adjusted) & 3 & $1.02(0.80-1.30)$ & $28 \% / 0.25$ \\
\hline LSCC (unadjusted) & 2 & $0.87(0.54-1.40)$ & $50 \% / 0.16$ \\
\hline LSCC (adjusted) & 2 & $0.92(0.70-1.21)$ & $0 \% / 0.62$ \\
\hline \multicolumn{4}{|l|}{ CC vs. CT $+\pi$ (unadjusted) } \\
\hline Overall & 4 & $0.96(0.70-1.31)$ & $43 \% / 0.15$ \\
\hline HWE (Yes) & 3 & $0.91(0.66-1.25)$ & $46 \% / 0.16$ \\
\hline HWE (No) & 1 & $3.65(0.45-29.89)$ & NA \\
\hline Asians & 3 & $1.58(0.93-2.71)$ & $0 \% / 0.70$ \\
\hline Caucasian & 1 & $0.74(0.50-1.09)$ & NA \\
\hline OSCC & 3 & $0.94(0.62-1.43)$ & $16 \% / 0.30$ \\
\hline
\end{tabular}


Table 4 Overall and subgroups meta-analysis of COX-2 rs5275 polymorphism and HNSCC risk (Continued)

\begin{tabular}{llll}
\hline LSCC & 2 & $1.02(0.40-2.60)$ & $63 \% / 0.10$ \\
CC + CT vs. TT (unadjusted and adjusted) & & & $0 \% / 0.41$ \\
Overall (unadjusted) & 4 & $0.90(0.77-1.04)$ & $0 \% / 0.78$ \\
Overall (adjusted) & 3 & $0.98(0.84-1.15)$ & $0 \% / 0.74$ \\
HWE (Yes-unadjusted) & 3 & $0.92(0.79-1.08)$ & $\mathrm{NA}$ \\
HWE (No-unadjusted) & 1 & $0.57(0.30-1.05)$ & $29 \% / 0.25$ \\
Asians (unadjusted) & 3 & $0.91(0.74-1.12)$ & $0 \% / 0.49$ \\
Asians (adjusted) & 2 & $1.00(0.79-1.27)$ & $\mathrm{NA}$ \\
Caucasian (unadjusted) & 1 & $0.88(0.70-1.10)$ & $\mathrm{NA}$ \\
Caucasian (adjusted) & 1 & $0.97(0.78-1.20)$ & $91 \% /<0.05$ \\
OSCC (unadjusted) & 3 & $1.09(0.55-2.16)$ & $2 \% / 0.31$ \\
OSCC (adjusted) & 2 & $1.01(0.80-1.27)$ & $7 \% / 0.30$ \\
LSCC (unadjusted) & 2 & $0.87(0.68-1.10)$ & $0 \% / 0.35$ \\
LSCC (adjusted) & 2 & $0.89(0.69-1.15)$ & \\
\hline OSCC & \\
\hline
\end{tabular}

OSCC oral squamous cell carcinoma; HNSCC head and neck squamous cell carcinoma; LSCC laryngeal squamous cell carcinoma; OR odds ratio; CI confidence interval; NA not available; HWE Hardy-Weinberg Equilibrium

usual method, based on unadjusted data $[7,8,13,14,35-$ 38], we also extracted the adjusted data and pooled them for investigating the interactions between genetic polymorphisms and environmental risk factors. Interestingly, the unadjusted data showed COX-2 rs689466 polymorphism might play a role in increased risk while the adjusted data showed a negative association. As we know, smoking and alcohol are the well known risk factors for $\operatorname{HNSCC}[2,4]$. One study by Mittal $\mathrm{M}$ et al. [31] adjusted age and gender only, while the other included studies all adjusted smoking and alcohol. While, there is a relevant meta-analysis by Zhao F et al. published in 2014 [39]. This meta-analysis focused on the association between COX-2 rs20417 polymorphism and digestive system cancer, including three studies of $\operatorname{HNSCC}[28,29,31]$ and revealed negative association based on the performance of 2 genetic models (GG + GC vs. GG: $\mathrm{OR}=0.66$, $95 \% \mathrm{CI}=0.29,1.50$; $\mathrm{C}$ vs. $\mathrm{G}: \mathrm{OR}=0.95,95 \% \mathrm{CI}=0.56$, 1.63). Whereas, our meta-analysis performed all recommended 5 genetic models, included more studies, and considered adjusted data. Furthermore, our metaanalysis investigated 3 polymorphisms at the same time and only focussed on HNSCC. Different cancers have their own histological characteristics and of course their own predisposing genes. The identical polymorphism in the same gene, different polymorphisms in the same gene, and identical polymorphism in different genes might reveal different associations in different cancers. Hence, our meta-analysis was more useful for reference. Also considering this point, we extracted the data for OSCC and LSCC if applicable. The results of all genetic models all showed negative association of OSSS, LSCC, and overall population. In addition we considered genetic background. We stratified the population by ethnicity to explore whether different ethnicities have different susceptibility. The results showed all these 3 polymorphisms in COX-2 gene regardless of genetic background of HNSCC.

As we know, COX-2 participated in cell proliferation and tumour microenvironment and associated with many types of cancer. However, our results showed there was non-association of COX-2 and HNSCC. The possible mechanism of the negative result due to the relative small sample size, which is not enough to detect the small genetic effect. Moreover, COX-2 gene polymorphisms were really not associated with HNSCC risk. Third, the compromise effect might be existed in the 3 polymorphisms of COX-2 or other environmental risk factors, such as green tea. Besides, the haplotype analysis was not performed because of limited information of included studies. However, to explore the true effects and possible mechanism between them remain necessary.

Heterogeneity is 1 of the important issues in genetic association meta-analysis. This limitation also existed in the present meta-analysis, some genetic models showed clear homogeneity while some showed heterogeneity, either in overall population or subgroup analyses (Tables 3, 4 and 5). The heterogeneity might be originated from different genotyping methods, environmental differences, or different lifestyles. However, we could not explore these factors due to the lack of individual data. Also, the number of eligible studies and sample sizes of for each polymorphism was insufficient. Statistical power is influenced by small sample sizes so owing to this limitation, we could not perform publication bias of any polymorphism. We did 
Table 5 Overall and subgroups meta-analysis of COX-2 rs20417 polymorphism and HNSCC risk

\begin{tabular}{|c|c|c|c|}
\hline Overall and subgroups & No. & OR (95 \% Cl) & Heterogeneity $\left(R^{2} \% / \mathrm{p}\right)$ \\
\hline \multicolumn{4}{|c|}{ C vs. G (unadjusted and adjusted) } \\
\hline Overall (unadjusted) & 5 & $1.13(0.62-2.05)$ & $92 \% /<0.10$ \\
\hline OSCC (unadjusted) & 4 & $1.22(0.52-2.89)$ & $94 \% /<0.10$ \\
\hline OSCC (adjusted) & 1 & $0.73(0.50-1.08)$ & NA \\
\hline Asians (unadjusted) & 4 & $1.22(0.52-2.89)$ & $94 \% /<0.10$ \\
\hline Caucasian (unadjusted) & 1 & $0.92(0.70-1.21)$ & NA \\
\hline HWE (Yes-unadjusted) & 4 & $0.78(0.52-1.18)$ & $83 \% /<0.10$ \\
\hline HWE (No-unadjusted) & 1 & $6.08(3.03-12.22)$ & NA \\
\hline \multicolumn{4}{|c|}{ CC vs. GG (unadjusted and adjusted) } \\
\hline Overall (unadjusted) & 5 & $1.17(0.25-5.46)$ & $80 \% /<0.10$ \\
\hline Overall (adjusted) & 2 & $0.53(0.25-1.11)$ & $0 \% / 0.71$ \\
\hline OSCC (unadjusted) & 4 & $1.79(0.10-31.00)$ & $89 \% /<0.10$ \\
\hline OSCC (adjusted) & 1 & $0.44(0.13-1.46)$ & NA \\
\hline Asians (unadjusted) & 4 & $1.79(0.10-31.00)$ & $89 \% /<0.10$ \\
\hline Caucasian (unadjusted) & 1 & $0.62(0.25-1.50)$ & NA \\
\hline HWE (Yes-unadjusted) & 4 & $0.55(0.27-1.13)$ & $0 \% / 0.67$ \\
\hline HWE (No-unadjusted) & 1 & $7.75(1.70-35.33)$ & NA \\
\hline \multicolumn{4}{|c|}{ GC vs. GG (unadjusted and adjusted) } \\
\hline Overall (unadjusted) & 5 & $0.69(0.36-1.35)$ & $0 \% / 0.75$ \\
\hline Overall (adjusted) & 2 & $0.90(0.68-1.19)$ & $9 \% / 0.29$ \\
\hline OSCC (unadjusted) & 4 & $0.80(0.30-2.09)$ & $0 \% / 0.50$ \\
\hline OSCC (adjusted) & 1 & $0.71(0.42-1.18)$ & NA \\
\hline Asians (unadjusted) & 4 & $0.80(0.30-2.09)$ & $0 \% / 0.50$ \\
\hline Caucasian (unadjusted) & 1 & $0.62(0.24-1.55)$ & NA \\
\hline HWE (Yes-unadjusted) & 4 & $0.62(0.30-1.29)$ & $0 \% / 0.98$ \\
\hline HWE (No-unadjusted) & 1 & $1.29(0.23-7.31)$ & NA \\
\hline \multicolumn{4}{|l|}{ CC vs. CG + GG (unadjusted) } \\
\hline Overall & 5 & $1.15(0.29-4.54)$ & $76 \% / 0.02$ \\
\hline OscC & 4 & $1.76(0.15-21.30)$ & $85 \% /<0.10$ \\
\hline Asians & 4 & $1.76(0.15-21.30)$ & $85 \% /<0.10$ \\
\hline Caucasian & 1 & $0.62(0.25-1.50)$ & NA \\
\hline HWE (Yes) & 4 & $0.58(0.29-1.18)$ & $0 \% / 0.84$ \\
\hline HWE (No) & 1 & $6.43(1.41-29.27)$ & NA \\
\hline \multicolumn{4}{|c|}{ CC + CG vs. GG (unadjusted and adjusted) } \\
\hline Overall (unadjusted) & 5 & $1.07(0.51-2.24)$ & $93 \% /<0.10$ \\
\hline OSCC (unadjusted) & 4 & $1.13(0.39-3.26)$ & $95 \% /<0.10$ \\
\hline OSCC (adjusted) & 1 & $0.22(0.12-0.39)$ & NA \\
\hline Asians (unadjusted) & 4 & $1.13(0.39-3.26)$ & $95 \% /<0.10$ \\
\hline Caucasian (unadjusted) & 1 & $0.90(0.70-1.30)$ & NA \\
\hline HWE (Yes-unadjusted) & 4 & $0.72(0.39-1.33)$ & $90 \% /<0.10$ \\
\hline HWE (No-unadjusted) & 1 & $6.45(2.90-14.35)$ & NA \\
\hline
\end{tabular}

OSCC oral squamous cell carcinoma; HNSCC head and neck squamous cell carcinoma; LSCC laryngeal squamous cell carcinoma; OR odds ratio; Cl confidence interval; NA not available; HWE Hardy-Weinberg Equilibrium 


\begin{tabular}{|c|c|c|c|c|c|c|c|c|c|c|}
\hline Study or Subgroup & $\begin{array}{l}\text { Cases } \\
\text { Events }\end{array}$ & s & $\begin{array}{l}\text { Contro } \\
\text { Events }\end{array}$ & $\begin{array}{l}\text { ols } \\
\text { Total }\end{array}$ & Weight & $\begin{array}{c}\text { Odds Ratio } \\
\text { M-H, Random, } 95 \% \mathrm{Cl}\end{array}$ & Year & $\begin{array}{r}\text { Odds } \\
\text { M-H, Rands }\end{array}$ & $\begin{array}{l}\text { Ratio } \\
\text { lom, } 95 \% \mathrm{Cl}\end{array}$ & \\
\hline Chiang 2008 & 104 & 594 & 173 & 560 & $21.3 \%$ & $0.47[0.36,0.63]$ & 2008 & - & & \\
\hline Lin 2008 & 42 & 356 & 39 & 410 & $19.7 \%$ & $1.27[0.80,2.02]$ & 2008 & & & \\
\hline Peters 2009 & 115 & 856 & 125 & 866 & $21.3 \%$ & $0.92[0.70,1.21]$ & 2009 & & & \\
\hline Mittal 2010 & 90 & 352 & 61 & 192 & $20.4 \%$ & $0.74[0.50,1.09]$ & 2010 & 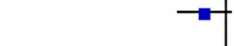 & & \\
\hline Lakshmi 2012 & 52 & 300 & 10 & 300 & $17.2 \%$ & $6.08[3.03,12.22]$ & 2012 & & & \\
\hline Total $(95 \% \mathrm{Cl})$ & & 2458 & & 2328 & $100.0 \%$ & $1.13[0.62,2.05]$ & & & & \\
\hline Total events & 403 & & 408 & & & & & & & \\
\hline \multicolumn{8}{|c|}{$\begin{array}{l}\text { Heterogeneity: } \mathrm{Tau}^{2}=0.42 ; \mathrm{Chi}^{2}=51.38, \mathrm{df}=4(\mathrm{P}<0.00001) ; \mathrm{I}^{2}=92 \% \\
\text { Test for overall effect: } Z=0.39(\mathrm{P}=0.70)\end{array}$} & $\begin{array}{lll} & 1 \\
0.05 & 0.2 & 1 \\
\text { Decreased risk }\end{array}$ & $\begin{array}{l}1 \\
\text { Increased risk }\end{array}$ & 20 \\
\hline
\end{tabular}

not confirm whether relevant publications published in languages other than English or Chinese existed, due to lack of right to search and ability to read, as such we may have missed some eligible studies. This limitation was also revealed in the included population. Our meta-analysis only included Asians and Caucasians, hence, our results had no value for other ethnicities. Finally, lacking a relevant recommended tool, we could not assess the methodological quality of included studies and did not performed subgroup analysis based on high vs. low quality. As such, we did not conduct the metaregression of methodological quality.

\section{Conclusion}

In summary, our meta-analysis based on crude and adjusted data showed that none of COX-2 rs689466, rs5275, and rs20417 polymorphisms was associated with risk of HNSCC. Due to limitations of our meta-analysis, such as insufficient sample sizes, our results should be treated with caution. We recommend further high quality studies, with large sample sizes and stratified by smoking status and alcohol consumption, be conducted to provide high level evidence for clinical implication.

\section{Abbreviations}

$\mathrm{Cl}$, confidence interval; COX-2, cyclooxygenase-2; HNSCC, Head and neck squamous cell carcinoma; HPV, Human papillomavirus; HWE, Hardy-Weinberg Equilibrium; LSXX, laryngeal squamous cell carcinoma; OR, Odds ratio; OSCC, Oral squamous cell carcinoma; PRISMA, Preferred Reporting Items for Systematic Reviews and Meta-Analyses; RevMan, Review Manager

\section{Acknowledgements}

We will thank to the all the authors of the included original studies.

\section{Funding}

This research was supported (in part) by the Nature Science Foundation of Hubei Province (2012FFB03902) and the Foundation of Evidence-based Medicine Nursery Fund of Taihe Hospital (EBM2013002 and EBM20140067), without commercial or not-for-profit sectors. The funders had no role in study design, data collection and analysis, decision to publish, or preparation of the manuscript. No additional external funding received for this study.
Availability of data and material

Meta-analysis is a secondary analysis which the data are all available from all included studies; hence, all the data and material can be found in the included original studies.

Authors' contributions

WDL and XTZ design this manuscript. JSWK and XJW performed systematic literature search. WH and JGC extracted data and performed statistical analysis. WDL and XJW wrote the manuscript. JSWK and XTZ reviewed the manuscript. All authors approved the final manuscript.

\section{Competing interests}

The authors declare that they have no competing interests.

\section{Consent for publication}

Not applicable.

Ethics approval and consent to participate Not applicable.

\section{Author details}

${ }^{1}$ Department of Stomatology, Taihe Hospital, Institute of Oral and Maxillofacial Surgery, Hubei University of Medicine, Shiyan 442000, China. ${ }^{2}$ Department of Stomatology, Daping Hospital \& Research Institute of Surgery, Third Military Medical University, Chongqing 400042, China. ${ }^{3}$ Chinese Cochrane Center, Chinese Evidence-Based Medicine Center Western China Hospital, West China Hospital, Sichuan University, Chengdu 610041, China. ${ }^{4}$ Department of Stomatology, Zhuhai People's Hospital, Zhuhai Hospital Affiliated with Jinan University, Zhuhai 519000, China. ${ }^{5}$ Department of Stomatology, Center for Evidence-Based and Translational Medicine, Zhongnan Hospital of Wuhan University, 169 Donghu Road, Wuhan 430071, China

Received: 3 May 2015 Accepted: 6 July 2016

Published online: 13 July 2016

\section{References}

1. Zeng XT, Luo W, Huang W, Wang Q, Guo Y, Leng WD. Tooth loss and head and neck cancer: a meta-analysis of observational studies. PLOS ONE. 2013;8(11), e79074.

2. Li Y, Mao Y, Zhang Y, Cai S, Chen G, Ding Y, Guo J, Chen K, Jin M. Alcohol drinking and upper aerodigestive tract cancer mortality: a systematic review and meta-analysis. Oral Oncol. 2014;50(4):269-75.

3. Zeng XT, Deng AP, Li C, Xia LY, Niu YM, Leng WD. Periodontal disease and risk of head and neck cancer: a meta-analysis of observational studies. PLOS ONE. 2013:8(10), e79017.

4. Wyss A, Hashibe M, Chuang SC, Lee YC, Zhang ZF, Yu GP, Winn DM, Wei Q, Talamini R, Szeszenia-Dabrowska N, et al. Cigarette, cigar, and pipe smoking and the risk of head and neck cancers: pooled analysis in the International Head and Neck Cancer Epidemiology Consortium. Am J Epidemiol. 2013;178(5):679-90 
5. Zeng XT, Leng WD, Zhang C, Liu J, Cao SY, Huang W. Meta-analysis on the association between toothbrushing and head and neck cancer. Oral Oncol. 2015;51(5):446-51.

6. Abogunrin S, Di Tanna GL, Keeping S, Carroll S, Iheanacho I. Prevalence of human papillomavirus in head and neck cancers in European populations: a meta-analysis. BMC Cancer. 2014;14(1):968.

7. Zeng XT, Luo W, Geng PL, Guo Y, Niu YM, Leng WD. Association between the TP53 codon 72 polymorphism and risk of oral squamous cell carcinoma in Asians: a meta-analysis. BMC Cancer. 2014;14:469.

8. Brunotto M, Zarate AM, Bono A, Barra JL, Berra S. Risk genes in head and neck cancer: A systematic review and meta-analysis of last 5 years. Oral Oncol. 2014;50(3):178-88.

9. Wang Y, Gao X, Wei F, Zhang X, Yu J, Zhao H, Sun Q, Yan F, Yan C, Li H, et al. The hOGG1 Ser326Cys polymorphism contributes to digestive system cancer susceptibility: evidence from 48 case-control studies. Tumour Biol. 2015;36(2): 1029-1038.

10. Wu W, Liu L, Yin Z, Guan P, Li X, Zhou B. Association of X-ray repair cross-complementing group 1 Arg194Trp, Arg399GIn and Arg280His polymorphisms with head and neck cancer susceptibility: a metaanalysis. PLoS ONE. 2014;9(1), e86798.

11. Zhang E, Cui Z, Xu Z, Duan W, Huang S, Tan X, Yin Z, Sun C, Lu L. Association between polymorphisms in ERCC2 gene and oral cancer risk: evidence from a meta-analysis. BMC Cancer. 2013;13:594.

12. Hu YY, Yuan $H$, Jiang GB, Chen $N$, Wen $L$, Leng WD, Zeng XT, Niu YM. Associations between XPD Asp312Asn polymorphism and risk of head and neck cancer: a meta-analysis based on 7,122 subjects. PLoS ONE. 2012;7(4), e35220.

13. Leng WD, He MN, Chen QL, Gong H, Zhang L, Zeng XT. Vascular endothelial growth factor (VEGF) gene polymorphisms and risk of head and neck cancer: a meta-analysis involving 2,444 individuals. Mol Biol Rep. 2013;40(10):5987-92.

14. Jiang L, Weng $H$, Chen MY, Zhang C, Zeng XT. Association between cyclooxygenase-2 gene polymorphisms and risk of periodontitis: a metaanalysis involving 5653 individuals. Mol Biol Rep. 2014:41(7):4795-801.

15. Fritsche E, Baek SJ, King LM, Zeldin DC, Eling TE, Bell DA. Functional characterization of cyclooxygenase-2 polymorphisms. J Pharmacol Exp Ther. 2001;299(2):468-76.

16. Wu H, Wu X, Wan G, Zhang S. Associations between Cox-2 rs20417 and rs5275 polymorphisms and the risk of hepatocellular carcinoma: a meta analysis. Int J Clin Exp Pathol. 2014;7(10):6898-905.

17. Peng Q, Yang S, Lao X, Tang W, Chen Z, Lai H, Wang J, Sui J, Qin X, Li S. Meta-analysis of the association between COX-2 polymorphisms and risk of colorectal cancer based on case-control studies. PLOS ONE. 2014;9(4), e94790.

18. Dai ZJ, Shao YP, Ma XB, Xu D, Tang W, Kang HF, Lin S, Wang M, Ren HT, Wang XJ. Association of the three common SNPS of cyclooxygenase-2 gene (rs20417, rs689466, and rs5275) with the susceptibility of breast cancer: an updated meta-analysis involving 34,590 subjects. Dis Markers. 2014:2014:484729

19. Yang X, Li B, Si T, Liu Y, Guo Z. Association between the 8473 T > C polymorphism of PTGS2 and prostate cancer risk: a metaanalysis including 24,716 subjects. Onkologie. 2013;36(4):182-6.

20. Yan WF, Sun PC, Nie CF, Wu G. Cyclooxygenase-2 polymorphisms were associated with the risk of gastric cancer: evidence from a meta-analysis based on case-control studies. Tumour Biol. 2013;34(6):3323-30.

21. Yang CY, Meng CL, Liao CL, Wong PY. Regulation of cell growth by selective COX-2 inhibitors in oral carcinoma cell lines. Prostaglandins Other Lipid Mediat. 2003;72(3-4):115-30

22. Saba NF, Choi M, Muller S, Shin HJ, Tighiouart M, Papadimitrakopoulou VA El-Naggar AK, Khuri FR, Chen ZG, Shin DM. Role of cyclooxygenase-2 in tumor progression and survival of head and neck squamous cell carcinoma. Cancer Prev Res (Phila). 2009;2(9):823-9.

23. Zeng $X$, Zhang Y, Kwong JS, Zhang C, Li S, Sun F, Niu Y, Du L. The methodological quality assessment tools for preclinical and clinical studies, systematic review and meta-analysis, and clinical practice guideline: a systematic review. J Evid Based Med. 2015;8(1):2-10.

24. Moher D, Liberati A, Tetzlaff J, Altman DG, Group P. Preferred reporting items for systematic reviews and meta-analyses: the PRISMA statement. BMJ. 2009;339:b2535.
25. Salanti G, Amountza G, Ntzani EE, loannidis JP. Hardy-Weinberg equilibrium in genetic association studies: an empirical evaluation of reporting, deviations, and power. Eur J Hum Genet. 2005;13(7):840-8.

26. Huedo-Medina TB, Sanchez-Meca J, Marin-Martinez F, Botella J. Assessing heterogeneity in meta-analysis: Q statistic or 12 index? Psychol Methods. 2006;11(2):193-206.

27. Campa D, Hashibe M, Zaridze D, Szeszenia-Dabrowska N, Mates IN, Janout V, Holcatova I, Fabianova E, Gaborieau V, Hung RJ, et al. Association of common polymorphisms in inflammatory genes with risk of developing cancers of the upper aerodigestive tract. Cancer Causes Control. 2007;18(4):449-55.

28. Chiang SL, Chen PH, Lee CH, Ko AM, Lee KW, Lin YC, Ho PS, Tu HP, Wu DC, Shieh TY, et al. Up-regulation of inflammatory signalings by areca nut extract and role of cyclooxygenase-2 -1195G > a polymorphism reveal risk of oral cancer. Cancer Res. 2008:68(20):8489-98.

29. Lin YC, Huang HI, Wang LH, Tsai CC, Lung O, Dai CY, Yu ML, Ho CK, Chen $\mathrm{CH}$. Polymorphisms of COX-2 -765G > C and p53 codon 72 and risks of oral squamous cell carcinoma in a Taiwan population. Oral Oncol. 2008;44(8):798-804.

30. Peters WH, Lacko M, Te Morsche RH, Voogd AC, Oude Ophuis MB, Manni JJ. COX-2 polymorphisms and the risk for head and neck cancer in white patients. Head Neck. 2009:31(7):938-43.

31. Mittal M, Kapoor V, Mohanti BK, Das SN. Functional variants of COX-2 and risk of tobacco-related oral squamous cell carcinoma in high-risk Asian Indians. Oral Oncol. 2010;46(8):622-6.

32. Lakshmi A, Muralidhar S, Kalyan Kumar C, Pavan Kumar A, Kalyana Chakravarthy P, Anjaneyulu V, Kaiser J. Cyclooxygenase-2-765G >C functional promoter polymorphism and its association with oral squamous cell carcinoma. J Investig Clin Dent. 2012;3(3):182-8.

33. Chang JS, Lo HI, Wong TY, Huang CC, Lee WT, Tsai ST, Chen KC, Yen CJ, Wu YH, Hsueh WT, et al. Investigating the association between oral hygiene and head and neck cancer. Oral Oncol. 2013;49(10):1010-7.

34. Niu Y, Yuan H, Shen M, Li H, Hu Y, Chen N. Association between cyclooxygenase-2 gene polymorphisms and head and neck squamous cell carcinoma risk. J Craniofac Surg. 2014;25(2):333-7.

35. Zeng XT, Liu DY, Kwong JS, Leng WD, Xia LY, Mao M. Meta-Analysis of Association Between Interleukin-1 beta C-511 T Polymorphism and Chronic Periodontitis Susceptibility. J Periodontol. 2015;86(6):812-9.

36. Mandal RK, Yadav SS, Panda AK, Khattri S. Vascular Endothelial Growth Factor 936 C > T Polymorphism Increased Oral Cancer Risk: Evidence from a Meta-Analysis. Genet Test Mol Biomarkers. 2013.

37. Xia LY, Zeng XT, Li C, Leng WD, Fan MW. Association between p53 Arg72Pro polymorphism and the risk of human papillomavirus-related head and neck squamous cell carcinoma: a meta-analysis. Asian Pac J Cancer Prev. 2013;14(10):6127-30.

38. Yan $Y$, Weng $H$, Shen ZH, Wu L, Zeng XT. Association between interleukin-4 gene-590 c/t,-33 c/t, and 70-base-pair polymorphisms and periodontitis susceptibility: a meta-analysis. J Periodontol. 2014;85(11):e354-62.

39. Zhao F, Cao Y, Zhu H, Huang M, Yi C, Huang Y. The-765G > C Polymorphism in the Cyclooxygenase-2 Gene and Digestive System Cancer: a Meta-analysis. Asian Pac J Cancer Prev. 2014;15(19):8301-10.

\section{Submit your next manuscript to BioMed Central and we will help you at every step:}

- We accept pre-submission inquiries

- Our selector tool helps you to find the most relevant journal

- We provide round the clock customer support

- Convenient online submission

- Thorough peer review

- Inclusion in PubMed and all major indexing services

- Maximum visibility for your research

Submit your manuscript at www.biomedcentral.com/submit 